\title{
広幅長方形断面水路におけるせき上げ背水曲線の簡略計算式
}

\section{A SIMPLE FORMULA FOR COMPUTING THE BACKWATER CURVE OF STEADY FLOW IN WIDE RECTANGULAR CHANNEL}

\author{
神田徹*・浜村吉昭** \\ By Tohru KANDA and Yoshiaki HAMAMURA
}

\begin{abstract}
A simplified equation for computing the backwater curve of steady flows in a wide rectangular channel is derived by using a perturbation method. The obtained formula is expressed in such a manner that water depth is given as a function of the distance from the downstream end, while most of the formulae previously proposed express the distance as a function of water depth. The results computed by the obtained formula are compared with those by the finite difference method, and it is proved that the formula has the satisfactorily high accuracy for practical computation of backwater curves. If neglecting the inertia term, or gradient of velocity head in the fundamental equation, the formula could be further simplified. But the omission of that term yields the large error of computation for such hydraulic condition that the ratio of normal water depth to critical water depth is less than about 2.
\end{abstract}

Keywords: backwater curve, nonuniform flow, gradually varied flow

\section{1. まえがき}

不等流水面形の計算は，水路断面形状や境界条件のい かんを問わず，今日では数値計算法によって容易に高精 度の計算結果が得られることは周知のとおりである.こ れに対して, 不等流の基礎方程式を積分して解析解の形 で計算式を得ることは古くから行われており, 水路断面 形に応じて種々の式が提案されてきた ${ }^{11}$. その代表的な ものとして, 広幅長方形断面水路を対象とした Bresse の式や一般断面水路に対して積分数表を利用して計算す る Chow の式などがある゙!.これらの式はいずれも，水 深がある値になる位置 (距離) を求めるという関数形で 表わされているので, 若干使いにくい.また, Bresse の式は Chezy の抵抗式を用いる場合の式である.

本文では一様な広幅長方形断面水路におけるせき上げ 背水について, Manning の抵抗式を用い, 数表を要せ ずに簡略に計算でき, 水深を距離 (位置) の関数として 表わす式を提示する. また従来, 解析解を得るために基 礎方程式における慣性項（速度水頭勾配）を無視するこ

\footnotetext{
* 正会員 工博 神戸大学教授 工学部土木工学科 （６557神戸市篗区六甲台町 1-1）

** 正会員 工修 神戸市土木局 ( ₹650 神戸市中央区加納町 6-5-1)
}

とがあるが，そのような仮定が計算精度上，妥当である かどうかを確かめるために慣性項省略によって生ずる誤 差について調べる.

\section{2. 不等流水面形の近似解}

広幅長方形断面水路における不等流の基礎方程式は次 式で与えられる.

$$
\begin{aligned}
& \frac{d}{d x}\left[\frac{\alpha v^{2}}{2 g}\right]+\frac{d h}{d x}+I-\frac{n^{2} v^{2}}{h^{4 / 3}}=0 \\
& q=h v=q_{0} \quad \text { (const. ) . }
\end{aligned}
$$

ここに, $h:$ 水深, $v:$ 断面平均流速, $q$ : 単位幅流量, $I:$ 水路床勾配 $; I=h_{0} / l, h_{0}$ : 単位幅流量 $q_{0}$ (一定) に対する等流水深, $l:$ 水路床高さが $h_{0}$ になる地点まで の下流端からの距離, $\alpha \doteqdot 1$ とする， $x$ 軸は下流端を原 点として上流に向かって正の方向にとる (Fig.1).

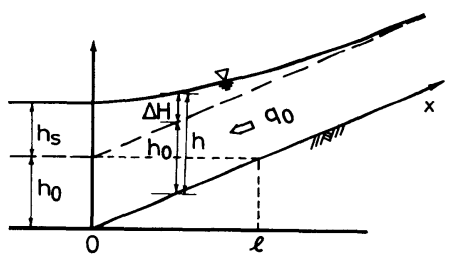

Fig. 1 Definition sketch. 
本研究で対象とする不等流水面形は，緩勾配水路にお けるせき上げ背水曲線（M1曲線）である，よって，境 界条件として下流端 $(x=0)$ の水深を次のように与える.

$h(0)=h_{0}+h_{s}$

ここに， $h_{s}$ : 等流水面を基準にした下流端の水位（ $h_{s}$ $>0)$.

諸量を次の関係;

$$
\left.\begin{array}{l}
x^{\prime}=x / l=I x / h_{0}, \quad h^{\prime}=h / h_{0} \\
v^{\prime}=v / \sqrt{g h_{0}}, \quad q^{\prime}=q /\left(h_{0} \sqrt{g h_{0}}\right)=h^{\prime} v^{\prime}
\end{array}\right\}
$$

を用いて無次元量に変換し, 式（1），（2）を書き直せ ば,

$$
\begin{aligned}
& \frac{d}{d x^{\prime}}\left[\frac{v^{\prime 2}}{2}\right]+\frac{d h^{\prime}}{d x^{\prime}}+1-I_{n} \frac{v^{\prime 2}}{h^{\prime 4 / 3}}=0 \\
& q^{\prime}=h^{\prime} v^{\prime}=-1 / \sqrt{I_{n}} \ldots \ldots \ldots \ldots \ldots \ldots \ldots \ldots \ldots \ldots \ldots \ldots \ldots
\end{aligned}
$$

ここに, $I_{n}=g n^{2} /\left(h_{0}^{1 / 3} I\right)=g h_{0}^{3} / q_{0}^{2}=h_{0}^{3} / h_{c}^{3}, h_{c}$ ：限界水

深. 緩勾配水路であるから， $I_{n}>1$.

また，境界条件式（3）は次式で表わされる.

$h^{\prime}(0)=1+h_{s}^{\prime}$

ここに, $h_{s}^{\prime}=h_{s} / h_{0}$.

式（5)，(6) 加次式となる.

$\frac{d h^{\prime}}{d x^{\prime}}\left[h^{\prime 10 / 3}-\frac{1}{I_{n}} h^{\prime 1 / 3}\right]+h^{\prime 10 / 3}-1=0$

式（8）の解を次のように表わす.

$h^{\prime}=1+h_{s}^{\prime} \phi_{1}+h_{s}^{\prime 2} \phi_{2}+h_{s}^{\prime 3} \phi_{3}+h_{s}^{\prime 4} \phi_{4}+\cdots$

右辺の第 5 項までをとって式 (8) に代入し, $h_{s}^{\prime}, h_{s}^{\prime 2}$, $h_{s}^{\prime 3}, h_{s}^{\prime 4}$ の係数をそれぞれゼロとおけば， $\phi_{1} \sim \phi_{4}$ に関す る方程式が次のように得られる.

$$
\begin{aligned}
\frac{d \phi_{1}}{d x^{\prime}}+\frac{10}{3} \frac{I_{n}}{I_{n}-1} \phi_{1}= & 0 \ldots \ldots \ldots \ldots \ldots \ldots \ldots \ldots \ldots \ldots \ldots \ldots \ldots \ldots \ldots \ldots \ldots \\
\frac{d \phi_{2}}{d x^{\prime}}+\frac{10}{3} \frac{I_{n}}{I_{n}-1} \phi_{2}= & \frac{5 I_{n}\left(13 I_{n}+5\right)}{9\left(I_{n}-1\right)^{2}} \phi_{1}^{2} \ldots \ldots \ldots \ldots \ldots \ldots \\
\frac{d \phi_{3}}{d x^{\prime}}+\frac{10}{3} \frac{I_{n}}{I_{n}-1} \phi_{3}= & -\frac{5 I_{n}\left(208 I_{n}^{2}+259 I_{n}+19\right)}{81\left(I_{n}-1\right)^{3}} \phi_{1}^{3} \\
& +\frac{10 I_{n}\left(13 I_{n}+5\right)}{9\left(I_{n}-1\right)^{2}} \phi_{1} \phi_{2} \cdots \cdots \cdots
\end{aligned}
$$

$$
\begin{aligned}
\frac{d \phi_{4}}{d x^{\prime}}+ & \frac{10}{3} \frac{I_{n}}{I_{n}-1} \phi_{4}=\frac{5 I_{n}}{243\left(I_{n}-1\right)^{4}}\left(988 I_{n}^{3}+2534 I_{n}^{2}+759 I_{n}\right. \\
& -7) \phi_{1}^{4}-\frac{5 I_{n}}{27\left(I_{n}-1\right)^{3}}\left(208 I_{n}^{2}+259 I_{n}+19\right) \phi_{1}^{2} \phi_{2} \\
& +\frac{10 I_{n}\left(13 I_{n}+5\right)}{9\left(I_{n}-1\right)^{2}} \phi_{1} \phi_{3}+\frac{5 I_{n}\left(13 I_{n}+5\right)}{9\left(I_{n}-1\right)^{2}} \phi_{2}^{2} \cdots \cdots(13)
\end{aligned}
$$

また，境界条件式（7）は次のようになる.

$\phi_{1}(0)=1, \quad \phi_{2}(0)=\phi_{3}(0)=\phi_{4}(0)=0$

式（10）（13）を式（14）のもとで解けば, $\phi_{1} \sim \phi_{4}$ がそれぞれ次のように与えられる。

$$
\phi_{1}=\exp \left\{-\frac{10 I_{n}}{3\left(I_{n}-1\right)} x^{\prime}\right\}
$$

$$
\begin{aligned}
& \phi_{2}= \frac{13 I_{n}+5}{6\left(I_{n}-1\right)}\left[\exp \left\{-\frac{10 I_{n}}{3\left(I_{n}-1\right)} x^{\prime}\right\}\right. \\
&\left.-\exp \left\{-\frac{20 I_{n}}{3\left(I_{n}-1\right)} x^{\prime}\right\}\right] \ldots \ldots \ldots \ldots \ldots \ldots \ldots(16) \\
& \phi_{3}= \frac{1}{108\left(I_{n}-1\right)^{2}}\left[\left(299 I_{n}^{2}+131 I_{n}+56\right) \exp \left\{-\frac{10 I_{n}}{3\left(I_{n}-1\right)} x^{\prime}\right\}\right. \\
&-\left(1014 I_{n}^{2}+780 I_{n}+150\right) \exp \left\{-\frac{20 I_{n}}{3\left(I_{n}-1\right)} x^{\prime}\right\} \\
&\left.+\left(715 I_{n}^{2}+649 I_{n}+94\right) \exp \left\{-\frac{10 I_{n}}{I_{n}-1} x^{\prime}\right\}\right] \ldots(17) \\
& \phi_{4}= \frac{1}{648\left(I_{n}-1\right)^{3}}\left[\left(1599 I_{n}^{3}+\frac{2102}{3} I_{n}^{2}+339 I_{n}+144\right)\right. \\
& \cdot \exp \left\{-\frac{10 I_{n}}{3\left(I_{n}-1\right)} x^{\prime}\right\}-\left(14365 I_{n}^{3}+14001 I_{n}^{2}\right. \\
&\left.+5691 I_{n}+935\right) \exp \left\{-\frac{20 I_{n}}{3\left(I_{n}-1\right)} x^{\prime}\right\}+\left(27885 I_{n}^{3}\right. \\
&\left.+36036 I_{n}^{2}+13401 I_{n}+1410\right) \exp \left\{-\frac{10 I_{n}}{I_{n}-1} x^{\prime}\right\} \\
&-\left(15119 I_{n}^{3}+\frac{68207}{3} I_{n}^{2}+8049 I_{n}+619\right) \\
&\left.\cdot \exp \left\{-\frac{40 I_{n}}{3\left(I_{n}-1\right)} x^{\prime}\right\}\right] \ldots \ldots \ldots \ldots \ldots \ldots(18) \\
&+\cdots \ldots \ldots \ldots \ldots \\
&
\end{aligned}
$$

結局，せき上げ背水曲線は式（15)〜（18）を用いて次 式で与えられる。

$h^{\prime}\left(x^{\prime}\right)=1+h_{s}^{\prime} \phi_{1}+h_{s}^{\prime 2} \phi_{2}+h_{s}^{\prime 3} \phi_{3}+h_{s}^{\prime 4} \phi_{4}$

または, $\Delta H^{\prime}=\Delta H / h_{0}=\left(h-h_{0}\right) / h_{0}$ とおけば,

$\frac{\Delta H^{\prime}}{h_{s}^{\prime}}=\frac{h-h_{0}}{h_{s}}=\phi_{1}+h_{s}^{\prime} \phi_{2}+h_{s}^{\prime 2} \phi_{3}+h_{s}^{\prime 3} \phi_{4}$

以下では, 式 (19), (20) の $\phi_{2}$ の項までを第二次近 似解， $\phi_{3}$ の項までを第三次近似解， $\phi_{4}$ の項までを第四 次近似解とよぶ。

\section{3. 解の精度}

\section{（1）慣性項省略の影}

式 (19) あるいは式 (20) の精度を調べる前に, 式（5） において第 1 項の慣性項（速度水頭勾配）を省略した場 合を考える.この慣性項省略の影響を数值計算によって 調べることにする．数値計算法としては，式（5)，（6） を差分式で表わし（水理公式集 ${ }^{4)}$, p. 198, 式 (2.1)), ニュートン法を用いて解いた。 以下, この解を差分解と よぶ.

式（5)，（6）の差分解と式（5）において慣性項を 省略した場合の差分解との差として，次式による誤差率 $\eta$ を求める.

$$
\eta=\left[\overline{\left\langle\Delta H_{1}^{\prime}-\Delta H_{2}^{\prime}\right\}^{2}}\right]^{1 / 2} / \overline{\Delta H_{1}^{\prime}}
$$

ここに， $\Delta H_{1}^{\prime}$ : 式 (5),（6）の差分解における $\Delta H^{\prime}$, $\Delta H_{2}^{\prime}$ : 式（5）の慣性項を省略した差分解における $\Delta H^{\prime}$. 記号一は河口から $x^{\prime}=1.4$ の地点までの場所的平均 
値を示す.

Table 1 は境界条件 $h_{s}^{\prime}$, 河道条件 $I_{n}$ に対する $\eta$ の值 を示す. $I_{n}=100,30$ の場合は慣性項省略による影響は ほとんどないが， $I_{n}$ が小さくなるにつれて省略の影響は 増大する．また， $h_{s}^{\prime}$ の大きさとはそれほど明確な関係 はない. Fig. 2 は式（5）の各項の値を河道に沿って示 したもものである. $I_{n}=5$ では $I_{n}=30$ の場合に比べて慣性 項がかなり大きな值をとる。これは， In が小さいほよ゙水 路床勾配が急で, 流速が大きいためである. 結局, $h_{0} / h_{c}=2 \sim 3$ を限界值として, $h_{0} / h_{c}$ がそれ以上の值で あれば慣性項を無視することができるが，それ以下の值 であれば慣性項無視は妥当ではない.

一方，慣性項を省略したときの近似解は次式で与えら れる ${ }^{3)}$.

$$
\begin{aligned}
\frac{\Delta H^{\prime}}{h_{s}^{\prime}}= & \exp \left[-\frac{10}{3} x^{\prime}\right]+\frac{13}{6} h_{s}^{\prime}\left\{\exp \left[-\frac{10}{3} x^{\prime}\right]\right. \\
& \left.-\exp \left[-\frac{20}{3} x^{\prime}\right]\right\}+\frac{13}{108} h_{s}^{\prime 2}\left\{23 \exp \left[-\frac{10}{3} x^{\prime}\right]\right. \\
& \left.-78 \exp \left[-\frac{20}{3} x^{\prime}\right]+55 \exp \left(-10 x^{\prime}\right)\right\}
\end{aligned}
$$

この式は, 式 (20) において $I_{n} \rightarrow \infty$ とすることによっ ても得ることができる.よって，慣性項を省略すること と $I_{n}$ が十分大きいことは等価である.このことからも， $I_{n}$ が小さくなれば省略の影響が大きくなるといえよう.

Table 1 のすべてのケースについて $\Delta H_{2}>\Delta H_{1}$ であ り，慣性項省略によって水位は高くなる．この理由は上 述のことと関係している.すなわち，不等流の水面形を

Table 1 Error of solution due to omission of inertia term.

(単位 \%)

\begin{tabular}{|c||c|c|c|c|}
\hline $\ln h_{5}$ & 0.2 & 0.3 & 0.4 & 0.5 \\
\hline 5 & 18.1 & 15.1 & 12.7 & 10.7 \\
\hline 10 & 8.2 & 6.9 & 5.8 & 5.0 \\
\hline 30 & 2.6 & 2.2 & 1.9 & 1.6 \\
\hline 100 & 0.8 & 0.6 & 0.6 & 0.5 \\
\hline
\end{tabular}

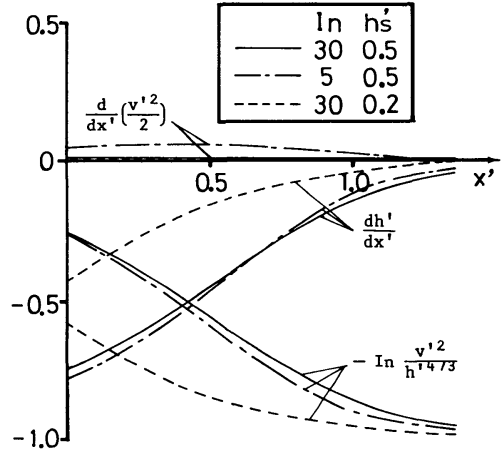

Fig. 2 Comparison of magnitude of terms in Eq. ( 5 ).
支配的に特性づけるのは式（15）の $\phi_{1}$ であるが, その 減衰率 $\alpha_{0}$ は次式で与えられる。

$$
\alpha_{0}=\frac{10 I_{n}}{3\left(I_{n}-1\right)}
$$

この式より， $I_{n}$ が小さければ減衰率は大きく，水位は低 い. ところが, 慣性項を省略することは $I_{n} \rightarrow \infty$ とする ことに相当するから，減衰率は小さく水位は高くなる. このため， In が小さい值であるほよ゙，慣性項省略によっ て水位は高く計算される.

\section{（2）近似解の精度}

Table 2 は式（5)，（6）の差分解に対する式 (22) の誤差および式 (20) の各近似解の誤差を, 式 (21) の $\eta$ によって示したものである.ただし，式（21）におい て $\Delta H_{1}^{\prime}$ は式（5)，（6）の差分解の $\Delta H^{\prime}, \Delta H_{2}^{\prime}$ は式 (22) あるいは式 $(20)$ で与えられる $\Delta H^{\prime}$ である.

この表のとおり, 式（22）の誤差率は式（20）の第三 次近似以上の解の誤差率に比べてかなり大きく, 特に $I_{n}$, $h_{s}^{\prime}$ が小さいほど大きい. 一方， $I_{n}$ が 30 以上であれば式 （5）の慣性項が省略できることは前述した。しかし， 式 (22) はこの省略した式に対する近似解であるために, この表のように $I_{n}$ が 30 以上でも誤差率は $5 \%$ を超える 大きさとなる。

式 (20) については, 第三次近似以上の解は $h_{s} \leqq 0.4$ ではほとんど $5 \%$ 以下の誤差率であり, 高精度の近似 解であるといえよう. 第三次近似解は第四次近似解に比 べて精度はそれほど劣らないので，その簡略さのゆえに 利用しやすいと思われる.この第三次近似解を整理して 再記すれば，次式のとおりである.

$$
\begin{aligned}
h= & h_{0}+h_{s} \exp \left\{-\frac{10 h_{0}^{2} I}{3\left(h_{0}^{3}-h_{c}^{3}\right)} x\right\} \\
& +\frac{h_{s}^{2}\left(13 h_{0}^{3}+5 h_{c}^{3}\right)}{6 h_{0}\left(h_{0}^{3}-h_{c}^{3}\right)}\left[\exp \left\{-\frac{10 h_{0}^{2} I}{3\left(h_{0}^{3}-h_{c}^{3}\right)} x\right\}\right. \\
& \left.-\exp \left\{-\frac{20 h_{0}^{2} I}{3\left(h_{0}^{3}-h_{c}^{3}\right)} x\right\}\right]+\frac{h_{s}^{3}}{108 h_{0}^{2}\left(h_{0}^{3}-h_{c}^{3}\right)^{2}}
\end{aligned}
$$

Table 2 Magnitude of $\eta$.

(単位 \%) 


$$
\begin{aligned}
& \cdot\left[\left(299 h_{0}^{6}+131 h_{0}^{3} h_{c}^{3}+56 h_{c}^{6}\right) \exp \left\{-\frac{10 h_{0}^{2} I}{3\left(h_{0}^{3}-h_{c}^{3}\right)} x\right\}\right. \\
& -\left(1014 h_{0}^{6}+780 h_{0}^{3} h_{c}^{3}+150 h_{c}^{6}\right) \exp \left\{-\frac{20 h_{0}^{2} I}{3\left(h_{0}^{3}-h_{c}^{3}\right)} x\right\} \\
& \left.+\left(715 h_{0}^{6}+649 h_{0}^{3} h_{c}^{3}+94 h_{c}^{6}\right) \exp \left\{-\frac{10 h_{0}^{2} I}{\left(h_{0}^{3}-h_{c}^{3}\right)} x\right\}\right]
\end{aligned}
$$

\section{4. 結 語}

一様な広幅長方形断面水路におけるせき上げ背水曲線 を簡略に計算するための式を導き，その計算精度を調べ た.ここに示した第三次近似解 (あるいは第四次近似解) は, $h_{s}^{\prime}=h_{s} / h_{0} \leqq 0.4, I_{n}=h_{0}^{3} / h_{c}^{3}=5 \sim 100$ の範囲におい て約 $5 \%$ 以下の誤差率であり, 実用的な水面形計算で は十分の精度と考えられる.

また，基礎方程式における慣性項の省略は $I_{n}$ が大き ければ $\left(I_{n} \geqq 30\right)$ 許されるが, その式からさらに近似解 を導けば（本文における式（22））誤差が重なって所要 の精度が得られない場合も起きる. したがって, あえて
慣性項を省略する場合には，水理条件と計算精度に留意 しなければならない。

ここに示した解析解（近似解）は計算精度においては 種々の数値計算法に及ばないけれだも，その関数形から 背水曲線の概略の形状, すなわちせき上げ水深の指数関 数的な減衰傾向やその減衰率などを知ることができる. また, 水理パラメーター $\left(h_{s}^{\prime}, I_{n}\right)$ の值が水面形によ゙の ように影響するかについても，この解をもとに検討する ことができる.
1) 本間 仁・安芸盿一編：物部水理学, 岩波書店, 1962 .
2) Chow, V.T. : Open-Channel Hydraulics, McGraw- Hill, 1959
3）神田 徹・浜村吉昭：河川感潮部における長周期水位変 動の解析，土木学会論文集，第 387 号／II-8，1987.
4）昭和 60 年版水理公式集, 土木学会, 1985.

(1987. 5.14 • 受付) 